\title{
Analysis of SubSynchronous Resonance with Three Level Twelve-Pulse VSC based SSSC
}

\author{
K. R. Padiyar and Nagesh Prabhu \\ Department of Electrical Engineering, \\ Indian Institute of Science, \\ Bangalore, 560012 INDIA \\ 080-293-2694 \\ krpyar@ee.iisc.ernet.in
}

\begin{abstract}
This paper presents the analysis and simulation of a series compensated system with a Static Synchronous Series Compensator (SSSC) as a part of the total compensation. The objective is to investigate the Subsynchronous Resonance (SSR) characteristic of the combined system. The IEEE first benchmark model (FBM) is considered for the analysis. The active series compensation is provided by a three level twelve pulse SSSC. The modelling and control details of a three level Voltage Source Converter(VSC) based SSSC are discussed.
\end{abstract}

The analysis of SSR with SSSC is carried out based on frequency domain method, eigenvalue analysis and transient simulation. The frequency domain method considers $D-Q$ model of SSSC for the computation of damping torque for quick check in determining torsional mode stability.

\section{INTRODUCTION}

Series compensation of long transmission lines is an economic solution to the problem of enhancing power transfer and improving system stability. However series compensated transmission lines connected to turbo generators can result in Subsynchronous Resonance (SSR) leading to adverse torsional interactions [1]. The series compensation can be achieved by suitable combination of passive elements and active FACTS controllers. SSSC is a new generation series FACTS controller based on VSC and has several advantages over TCSC based on thyristor controllers. The three level converter topology greatly reduces the harmonic distortion on the ac side [2]-[4]. The main work presented in this paper is the analysis and simulation of a series compensated system with three level twelve-pulse VSC based SSSC. The objective is to investigate the SSR characteristic of the combined system.

\section{POWER SYSTEM MODELLING}

The system considered is a IEEE FBM [5]. The complete electromechanical system is represented schematically in Figure 1, which consists of a generator, turbine, and series compensated long transmission line with SSSC injecting a reactive voltage in series with the line. The modelling aspects

$0-7803-7651-X / 03 / \$ 17.00$ ๔ 3003 IEES

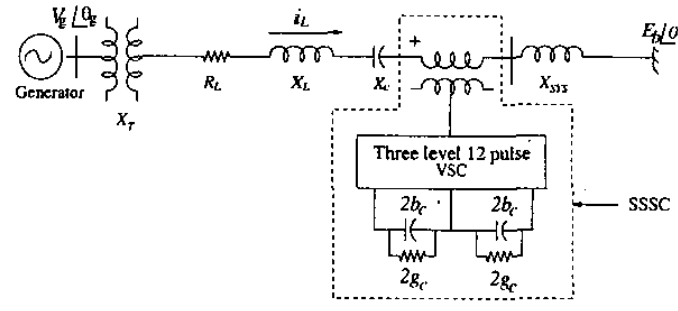

(a) Electrical System

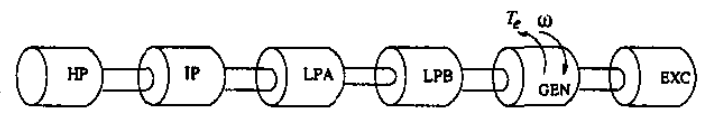

(b) Sixmass Mechanical System

Figure 1. IEEE FBM with SSSC

of the electromechanical system comprising the generator, the mass-spring mechanical system, the excitation system, power system stabilizer (PSS), torsional filter, the transmission line containing the conventional series capacitor are given in detail in reference [1],[6]. The combined system equations in $D-Q$ variables are linearized at an operating point to carry out the eigenvalue analysis. However transient simulation requires detailed modelling of SSSC considering switching action of VSC.

\section{MODELLING OF SSSC WITH THREE LEVEL VSC}

Switching functions

The Figure 2 shows the basic configuration of a three level bridge used for SSSC.

In the power circuit of a SSSC, the converter is usually either a multi-pulse or a multilevel configuration. In this paper a combination of multi-pulse and three level configuration is studied. The analysis is carried on 12-pulse converter with 3level poles. The harmonics are dependent on the capacitance and the operating point of the SSSC. In three level bridge, the phase potentials can be modulated between three levels instead of two. Each phase can be connected to the positive 


\section{Power System Stability and Control / 77}

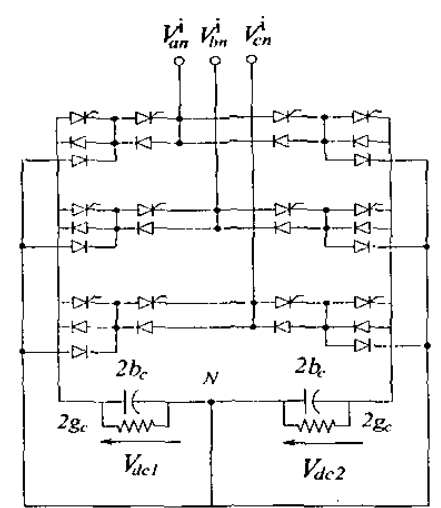

Figure 2. Three level six pulse bridge

$\mathrm{dc}$ terminal, the midpoint on the dc side or the negative dc terminal. The switching function for phase ' $a$ ' is shown in Figure 3.

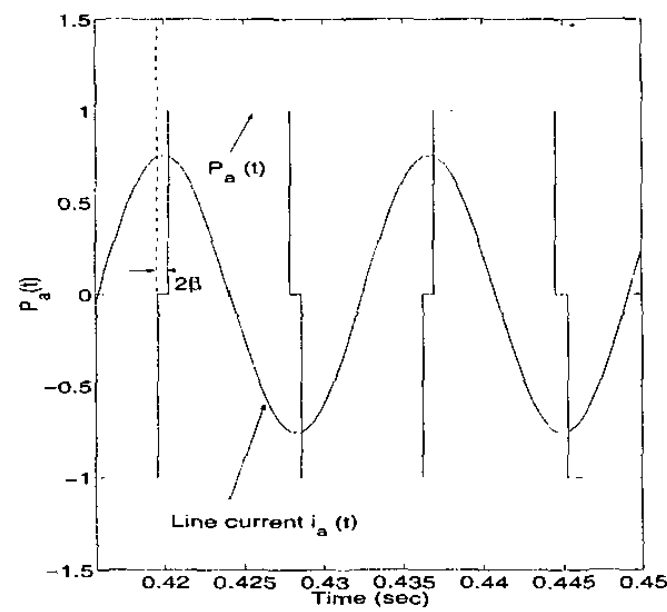

Figure 3. Switching function for a three level converter

The switching functions of phase $\mathrm{b}$ and $\mathrm{c}$ are similar but phase shifted successively by $120^{\circ}$ in terms of the fundamental frequency. Assuming that the dc capacitor voltages $V_{d c 1}=V_{d c 2}=\frac{V_{d c}}{2}$, the converter terminal voltages with respect to the mid point of dc side ' $N$ ' can be obtained as,

$$
\left[\begin{array}{l}
V_{a N}^{i} \\
V_{b N}^{i} \\
V_{c N}^{i}
\end{array}\right]=\left[\begin{array}{c}
P_{a}(t) \\
P_{b}(t) \\
P_{c}(t)
\end{array}\right] \frac{V_{d c}}{2}
$$

and the converter output voltages with respect to the neutral of transformer can be expressed as,

$$
\left[\begin{array}{c}
V_{a n}^{i} \\
V_{b n}^{i} \\
V_{c n}^{i}
\end{array}\right]=\left[\begin{array}{c}
S_{a}(t) \\
S_{b}(t) \\
S_{c}(t)
\end{array}\right] V_{d c}
$$

where, $S_{a}(t)=\frac{P_{a}(t)}{2}-\left[\frac{P_{a}(t)+P_{b}(t)+P_{c}(t)}{6}\right]$

$S_{a}(t)$ is the switching function for phase 'a' of a 6-pulse 3level VSC. Similarly for phase 'b', $S_{b}(t)$ and for phase 'c', $S_{c}(t)$ can be derived. The peak value of the fundamental and harmonics in the phase voltage $V_{a n}^{i}$ are found by applying Fourier analysis on the phase voltage and can be expressed as,

$$
V_{a n(h)}^{i}=\frac{2}{h \pi} V_{d c} \cos (h \beta)
$$

Where, $h=1,5,7,11,13$ and $\beta$ is the dead angle (period) during which the converter pole output voltage is zero. We can eliminate the 5 th and 7 th harmonics by using a twelve-pulse VSC, which combines the output of two six-pulse converters using transformers. The switching functions for a twelve-pulse converter are given by:

$$
\begin{aligned}
& S_{a}^{12}(t)=S_{a}(t)+\frac{1}{\sqrt{3}}\left(S_{a}^{\prime}(t)-S_{c}^{\prime}(t)\right), \\
& S_{b}^{12}(t)=S_{b}(t)+\frac{1}{\sqrt{3}}\left(S_{b}^{\prime}(t)-S_{a}^{\prime}(t)\right), \\
& S_{c}^{12}(t)=S_{c}(t)+\frac{1}{\sqrt{3}}\left(S_{c}^{\prime}(t)-S_{b}^{\prime}(t)\right) \\
& \text { where } S_{x}^{\prime}(t)=S_{x}\left[t+\frac{2 \pi}{\omega_{o}} \frac{1}{12}\right], x=a, b \text { and } c
\end{aligned}
$$

If the switching functions are approximated by their fundamental components (neglecting harmonics) for a 12-pulse three level converter, we get:

$$
V_{a n}^{i}=\frac{4}{\pi} V_{d c} \cos (\beta) \sin \left(\omega_{o} t+\phi+\gamma\right)
$$

and $V_{b n}^{i}, V_{c n}^{i}$ are phase shifted successively by $120^{0}$.

The line current is given by $i_{a}=\sqrt{\frac{2}{3}} I_{a} \sin \left(\omega_{o}+\phi\right)$ and $i_{b}, i_{c}$ are phase shifted successively by $120^{\circ}$. Note that $\gamma$ is the angle by which the fundamental component of converter output voltage leads the line current. It should be noted that $\gamma$ is nearly equal to $\pm \frac{\pi}{2}$ depending upon whether SSSC injects inductive or capacitive voltage. Neglecting converter losses we can get the expression for dc capacitor current as,

$$
\left[\begin{array}{lll}
i_{d c}
\end{array}\right]=-\left[\begin{array}{lll}
S_{a}^{12}(t) & S_{b}^{12}(t) & S_{c}^{12}(t)
\end{array}\right]\left[\begin{array}{c}
i_{a} \\
i_{b} \\
i_{c}
\end{array}\right]
$$

A particular harmonic reaches zero, when $2 \beta=\frac{180^{\circ}}{h}$. At $\beta_{\text {optimum }}=7.5^{\circ}$, the three level 12-pulse converter behaves nearly like a two level 24-pulse converter as 11 th and 13 th harmonics are negligibly small.

\section{Type-1 controller}

It would be desirable to vary the magnitude of ac output voltage without having to change the magnitude of the dc voltage. This can only be possible by PWM with two level topology which demands higher switching frequency and leads to increased losses. The three level converter topology can achieve the goal by varying dead angle $\beta$ with fundamental switching frequency. The converter that allows the variation of instantaneous values of both $k_{m}$ (modulation index) and $\gamma$ (the phase angle of converter output voltage) are classified as TYPE-I converters [7]. The Type- 1 controller structure for SSSC is shown in Figure 4. In this controller, both magnitude 
TENCON $2003 / 78$

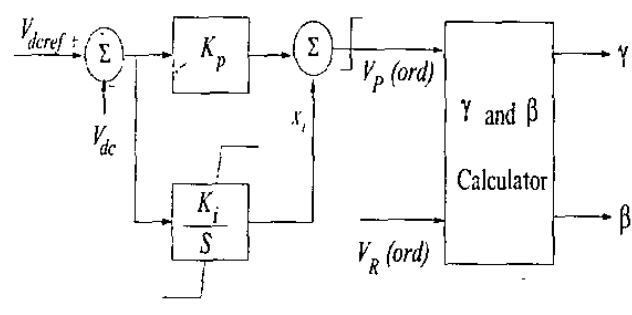

Figure 4. Real and reactive voltage controller

which is a function of $\cos \beta$ (for a constant $V_{d c}$ ) and phase angle $\gamma$ of the converter voltage are used to control reactive and real voltage. The real voltage is used to maintain capacitor voltage at a constant value. It should be noted that harmonic content of the SSSC injected voltage would vary depending upon the operating point since magnitude control will also govern the switching. The reference value of the capacitor voltage should be set at a value at which harmonics are minimum for a given operating point. In Figure $4, \gamma$ and $\beta$ are calculated as:

$$
\begin{gathered}
\gamma=\tan ^{-1}\left[\frac{V_{R(\text { ord })}}{\left.V_{P(\text { ord })}\right)}\right] \\
\beta=\cos ^{-1}\left[\frac{\sqrt{V_{P(\text { ord })}^{2}+V_{R(o r d)}^{2}}}{k v_{d c}}\right]
\end{gathered}
$$

\section{Mathematical model in $D-Q$ variables}

When the harmonics are neglected, SSSC can be modelled by transforming the 3 phase voltages and currents in to $\mathrm{D}-\mathrm{Q}$ variables using Kron's transformation which is power invariant. The equations in $D-Q$ variables are time invariant and are given by,

$$
\begin{aligned}
& V_{D}^{i}=k_{m} V_{d c} \sin (\phi+\gamma) \\
& V_{Q}^{i}=k_{m} V_{d c} \cos (\phi+\gamma)
\end{aligned}
$$

We can define injected reactive and real voltages in terms of variables in $\mathrm{D}-\mathrm{Q}$ frame $\left(V_{D}^{i}\right.$ and $\left.V_{Q}^{i}\right)$ as follows.

$$
\begin{aligned}
& V_{R}=V_{D}^{i} \cos \phi-V_{Q}^{i} \sin \phi \\
& V_{P}=V_{D}^{i} \sin \phi+V_{Q}^{i} \cos \phi
\end{aligned}
$$

Here, positive $V_{R}$ implies that SSSC injects inductive voltage and positive $V_{P}$ implies that it draws real power to meet losses.

The dc side capacitor is described by the dynamical equation as,

$$
\frac{d v_{d c}}{d t}=-\frac{g_{c} \omega_{b}}{b c} v_{d c}-i_{d c} \frac{\omega_{b}}{b c}
$$

where $i_{d c}=-\left[k_{m} \sin (\phi+\gamma) i_{D}+k_{m} \cos (\phi+\gamma) i_{Q}\right]$ and $k_{m}=k \cos \beta ; k=\frac{2 \sqrt{6}}{\pi}$ for a 12 pulse converter.

\section{ANALYSIS OF SSR}

The analysis is carried out on the IEEE FBM based on the following initial operating condition and assumptions.

1. The generator delivers 0.9 p.u. power to the transmission system.

2. The input mechanical power to the turbine is assumed constant.

3. The total series compensation level is set at 0.6 p.u.

4. For transient simulation, a step decrease of $10 \%$ mechanical input torque applied at $0.5 \mathrm{sec}$ and removed at $I \mathrm{sec}$ is considered in all case studies.

\section{Damping torque analysis}

Frequency domain methods are used to screen the system conditions that give rise to potential SSR problems. The significance of this approach is that it allows planners to establish acceptable series compensation levels for a specified stage of system development. Damping torque method is a frequency domain method, which gives a quick check to determine the torsional mode stability. In this analysis, the generator is modelled by a constant voltage source $\left(E^{\prime}\right)$ behind a transient reactance $\left(X_{d}^{\prime}\right)$. At any given oscillation frequency of the generator rotor, the component of electrical torque in phase with the rotor speed is termed as damping torque. The expression for determining damping torque coefficient $\left(T_{d e}\right)$ without SSSC in the transmission network is derived in reference [1]. The electrical torque $\left(\Delta T_{c}\right)$ as a function of the change in per unit rotor speed $\left(\Delta S_{m}\right)$ can be derived from the knowledge of the impedance functions. At the generator internal bus the following equation applies.

$$
\left[\begin{array}{l}
\Delta i_{D} \\
\Delta i_{Q}
\end{array}\right]=-\left[\begin{array}{ll}
Y_{D D} & Y_{D Q} \\
Y_{Q D} & Y_{Q Q}
\end{array}\right]\left[\begin{array}{l}
\Delta e_{D} \\
\Delta e_{Q}
\end{array}\right]
$$

For the simplified generator model, the expression for damping torque can be written as,

$$
T_{D e}(\omega)=\Re\left[Y_{Q D}(j \omega) \frac{\omega_{0}}{j \omega}+Y_{Q Q}(j \omega)\right]\left(E^{\prime}\right)^{2}
$$

In obtaining 14, it is necessary to express the impedance function $\left[Z_{s}\right]$ of SSSC in D-Q frame in the form (see Appendix -A) as given below,

$$
\begin{gathered}
{\left[\begin{array}{c}
\Delta V_{D}^{i} \\
\Delta V_{Q}^{i}
\end{array}\right]=\left[Z_{s}\right]\left[\begin{array}{l}
\Delta i_{D} \\
\Delta i_{Q}
\end{array}\right]} \\
\text { where, }\left[Z_{s}\right]=\left[\begin{array}{ll}
Z_{s D D} & Z_{s D Q} \\
Z_{s Q D} & Z_{s Q Q}
\end{array}\right]
\end{gathered}
$$

Results-The damping torque due to electrical network is evaluated in the range of frequency of 10-360 rad/sec for the following cases using equation-14.

case-1: Without SSSC

case-2: With SSSC

In case- 1 , the series compensation of $60 \%$ is completely met 


\section{Power System Stability and Control / 79}

by fixed capacitor and in case-2, hybrid compensation is used wherein $45 \%$ of compensation is met by fixed capacitor and the remaining $15 \%$ by SSSC. The variation of damping torque with frequency for both cases is shown in Figure 5.

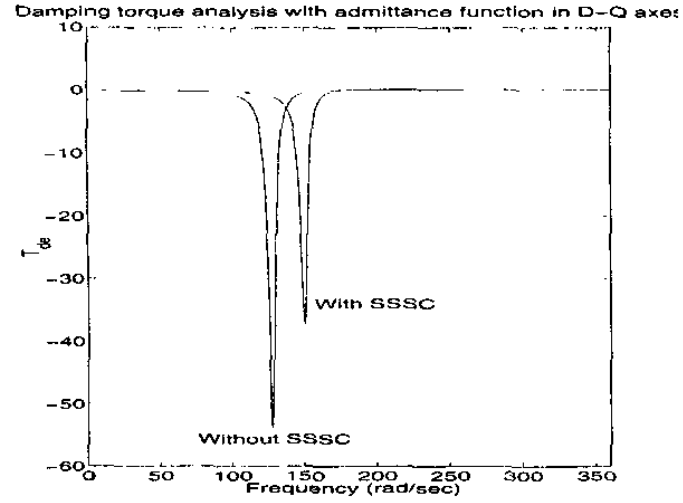

Figure 5. Damping torque with admittance function in D-Q axes

It is to be noted that, in case-1, the damping torque is maximum negative at a frequency of around $127 \mathrm{rad} / \mathrm{sec}$ which matches with the natural frequency of torsional mode-2 and adverse torsional interactions are expected. In case-2, maximum undamping occurs at a frequency about $150 \mathrm{rad} / \mathrm{sec}$. Since this network frequency mode is not coinciding with any of the torsional modes, the system is stable.

The eigen values of the system with classical model of generator, neglecting mechanical damping, are evaluated to correlate with the results of damping torque. The comparison of numerical value of damping torque coefficient $\left(T_{d e}\right)$ at critical torsional mode frequency of about $127 \mathrm{rad} / \mathrm{sec}$ and eigenvalues are given in Table 1.

Table 1. Damping torque with admittance function in D-Q axes

\begin{tabular}{|c|c|c|c|c|}
\hline $\begin{array}{c}\text { Sl. } \\
\text { No. }\end{array}$ & Case & $T_{d e}$ & $\sigma=\frac{T_{d e}}{4 H_{m 2}}$ & $\begin{array}{c}\text { Real part of } \\
\text { Eigen value }\end{array}$ \\
\hline 1 & $\begin{array}{c}\text { Without } \\
\text { SSSC }\end{array}$ & -52.9650 & 0.4763 & 0.4255 \\
\hline 2 & $\begin{array}{c}\text { With } \\
\text { SSSC }\end{array}$ & -1.0749 & 0.0097 & 0.0103 \\
\hline
\end{tabular}

Referring to Table 1, it is to be noted that there exists a fairly good correlation between damping torque and real part of eigenvalue.

\section{Eigenvalue analysis}

In this analysis generator model $(2.2)$ is considered. The SSSC equations along with the equations representing electromechanical system considering mechanical damping are linearized at the operating point. The eigenvalues of system matrix are computed and are given in Table 2 . The difference in the real part of eigenvalues given in Tables 1 and 2 is due to the fact that the classical model gives optimistic results compared to (2.2) model of generator. This is because classical model neglects interactions due to induction generator effect. It is to be noted that, inclusion of SSSC leads to a stable system and reduces the potential risk of SSR problem.

Table 2. Eigen values of the combined system

\begin{tabular}{|c|c|c|}
\hline \multirow{2}{*}{$\begin{array}{c}\text { Torsional } \\
\text { Mode }\end{array}$} & \multicolumn{2}{|c|}{ Eigen Value } \\
\hline & Without $S S S C$ & With SSSC \\
\hline 0 & $-1.744 \pm j \quad 8.964$ & $-1.302 \pm j \quad 8.134$ \\
\hline 1 & $-0.205 \pm j \quad 99.451$ & $-0.209 \pm j \quad 99.132$ \\
\hline 2 & $0.645 \pm j 127.040$ & $-0.069 \pm j 127.050$ \\
\hline 3 & $-0.646 \pm j 160.420$ & $-0.645 \pm j 160.210$ \\
\hline 4 & $-0.365 \pm j 202.820$ & $-0.370 \pm j 202.800$ \\
\hline 5 & $-1.850 \pm j 298.170$ & $-1.850 \pm j 298.170$ \\
\hline $\begin{array}{c}\text { Network } \\
\text { mode }\end{array}$ & $-1.942 \pm j 127.050$ & $-1.533 \pm j 150.080$ \\
\hline $\begin{array}{l}\text { Network } \\
\text { mode }\end{array}$ & $-2.990 \pm j 626.810$ & $-2.496 \pm j 583.000$ \\
\hline
\end{tabular}

\section{Transient simulation}

The eigenvalue analysis uses equations in $D-Q$ variables where the switching functions are approximated by their fundamental components (converter switchings are neglected). To validate the results obtained from damping torque and eigenvalue analysis, the transient simulation should be carried out using detailed model of SSSC which considers the switching of three phase converter. Hence the three level 12-pulse converter is modelled by generating switching functions. The transient simulation of the combined system with detailed three phase model of SSSC has been carried out using MATLAB-SIMULINK [8]. The system response for simulation without SSSC is shown in Figure 6. The simulation results of combined system with detailed three phase model of SSSC is shown in Figure 7.

\section{CONCLUSIONS}

In this paper we have presented the analysis and simulation of series compensated system with SSSC. The modelling details of 12-pulse three level VSC based SSSC is presented. It is observed that the SSSC with constant reactive voltage injection mode is SSR neutral.

\section{ACKNOWLEDGEMENT}

The financial support received from the Department of Science and Technology, Government Of India under the project titled "Dynamic security assessment and control of power grids" is gratefully acknowledged. 

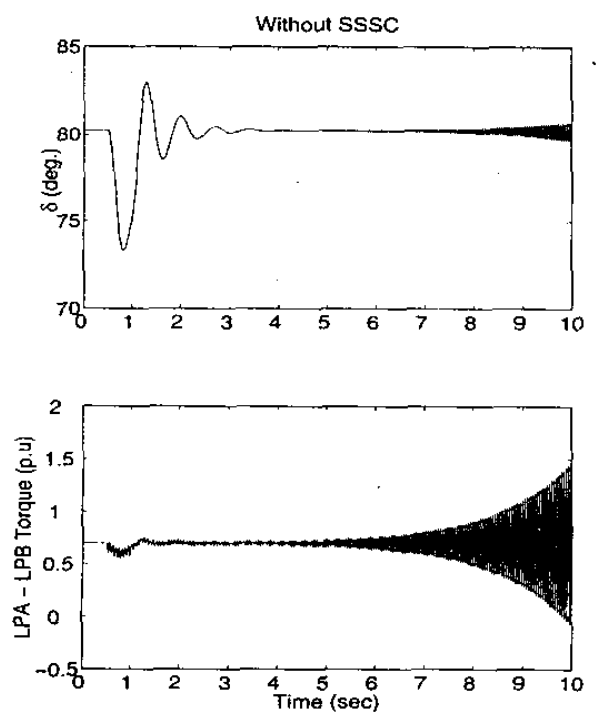

Figure 6. System response without SSSC
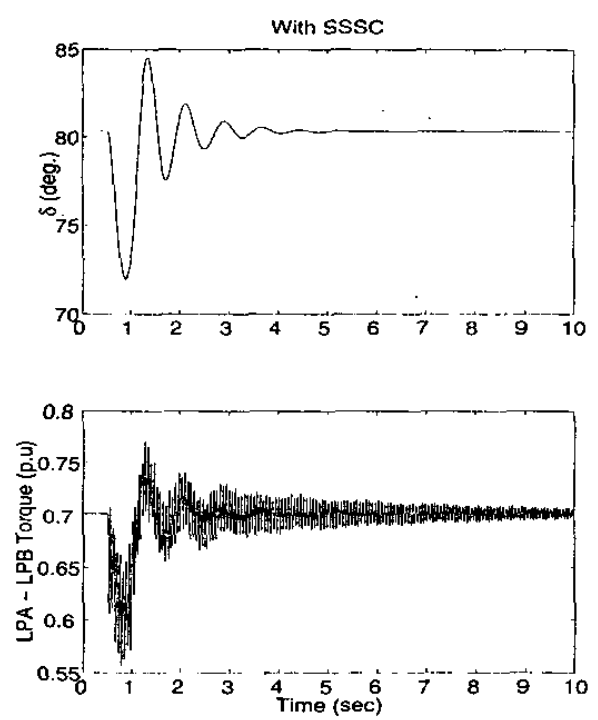

Figure 7. System response with detailed three phase model of SSSC

\section{APPENDIX - A}

To obtain $\left[Z_{s}\right]$ equations 6 to 12 are linearized at the operating point and expressed as,

$$
\begin{aligned}
& {\left[\begin{array}{l}
\Delta \dot{v}_{d c} \\
\Delta X_{1}
\end{array}\right]=\left[A_{s}\right]\left[\begin{array}{l}
\Delta v_{d c} \\
\Delta X_{1}
\end{array}\right]+\left[B_{s}\right]\left[\begin{array}{l}
\Delta i_{D} \\
\Delta i_{Q}
\end{array}\right]} \\
& {\left[\begin{array}{l}
\Delta V_{D}^{i} \\
\Delta V_{Q}^{i}
\end{array}\right]=\left[C_{s} \cdot\left[\begin{array}{l}
\Delta v_{d c} \\
\Delta X_{1}
\end{array}\right]+\left[D_{s}\right]\left[\begin{array}{l}
\Delta i_{D} \\
\Delta i_{Q}
\end{array}\right]\right.} \\
& {\left[\begin{array}{l}
\Delta V_{D}^{i} \\
\Delta V_{Q}^{i}
\end{array}\right]=\left[Z_{s}\right]\left[\begin{array}{l}
\Delta i_{D} \\
\Delta i_{Q}
\end{array}\right]}
\end{aligned}
$$$$
\text { where, }
$$

$$
\left[Z_{s}\right]=\left[C_{s}\right]\left[s I-A_{s}\right]^{-1}\left[B_{s}\right]+\left[D_{s}\right]
$$

\section{APPENDIX - B}

System Data:

The electromechanical system consists of a 892.4 MVA generator connected to a $500 \mathrm{Kv}$ transmission system. The data for electromechanical system pertaining to IEEE FBM model is given in references [1],[5]. All data are in p.u.

Transmission system data:

$X_{T}=0.14, R_{L}=0.02, X_{L}=1.0, X_{C}=0.6$ or 0.45 , $X_{S Y S}=0.06, E_{b}=1 \angle 0^{0}, V_{g}=1 \angle \theta_{g}$

Excitation system:

$K_{A}=200, T_{A}=0.025, E_{f d}(\max )=6.0$, $E_{f d}(\min )=-6.0$

Power system stabilizer and Torsional filter:

$T_{w}=10, K_{p s s}=6.0, T_{1}=0.1, T_{2}=0.01, \omega_{n}=22$ $\mathrm{rad} / \mathrm{sec}, \zeta=0.5, V_{s}(\max )=0.1, V_{s}(\min )=-0.1$

SSSC on its own base (150 MVA, $400 \mathrm{Kv}$ ):

$R_{c}=78.7, g_{c}=\frac{1}{R_{r}}, b_{c}=1.136, K_{p}=1, K_{i}=1$, Transformer tap $=\frac{1}{8}$

\section{REFERENCES}

[1] K. R. Padiyar, Analysis of Subsynchronous Resonance in power systems, Boston: Kluwer Academic Publishers, 1999.

[2] R. W. Menzis and Yiping Zhuang, "Advanced static compensation using a multilevel GTO thyristor inverter," IEEE Transactions on Power Delivery, Vol. I0, No.2, April 1995.

[3] J. B. Ekanayake and N. Jenkins, "Mathematical models of a three level advanced static var compensator," IEE Proc.- Generation Transm. distrib, vol. 144, No.2, March 1997.

[4] N. G. Hingorani and L. Gyugyi, Understanding FACTS, New York: IEEE Press, 2000.

[5] "First bench mark model for computer simulation of Subsynchronous resonance," IEEE Transactions on $P A S$, vol. 96, no. 5, pp. 1565-1572, sep/oct 1977.

[6] K. R. Padiyar, Power System Dynamics - Stability and Control-Second edition, Hyderabad: B.S.Publications, 2002.

[7] Schauder and Mehta, "Vector analysis and control of advanced static VAR compensators," IEE Proc.-c, vol. 140, no. 4, pp. 299-306, July 1993.

[8] The Math works Inc, "Using MATLAB-SIMULINK", 1999. 